\title{
A aprendizagem durante a pandemia: muito mais que pedras no caminho da educação superior
}

Ana Carolina de Araújo Silva

Professora do curso de Comunicação Institucional da Universidade Federal do Paraná (UFPR). Doutora em Comunicação pela Universidade Metodista de São Paulo. Membro do grupo de pesquisa COMXXI.

E-mail: anacarolaraujosilva@ufpr.br

Claudia Irene de Quadros

Professora do Programação de Pós-Graduação em Comunicação da Universidade Federal do Paraná (PPGCOM-UFPR). Possui pós-doutorado em Comunicaşão pela Universitat Pompeu Fabra (UPF) e é doutora em Comunicação pela Universidad de La Laguna (ULL).

E-mail: clauquadros@gmail.com

Juliane Martins

Professora do curso de Comunicação Institucional da Universidade Federal do Paraná

(UFPR). Doutoranda em Ciências da Comunicação pela Escola de Comunicações e Artes da Universidade de São Paulo (ECA-USP). Membro do grupo de pesquisa COMXXI.

E-mail: professorajuliane@ufpr.br

Resumo: Este artigo procura refletir sobre a aprendizagem na educação superior durante a pandemia da Covid-19, que obrigou muitas instituições a adotarem aulas remotas. A pandemia colocou em evidência tropeços e acertos nesta área. Por isso, apresentamos um breve panorama sobre a educação superior para poder melhor compreendê-la neste momento de isolamento social. As experiências aqui relatadas mostram diferentes caminhos tomados: a do professor que vira estudante para aprender novas demandas; a do gestor que planeja apoiar o docente habituado com aulas presenciais; e a do professor como mediador, que observa o discente como o protagonista do processo de aprendizagem. Em todas as trajetórias, observamos uma trilha sem volta: a necessidade do (re)nascimento da docência e o desenvolvimento de metodologias ativas para melhorar a qualidade do aprendizado.

Palavras-chave: pandemia; experiências; aprendizagem; coronavírus; ensino remoto.
Abstract: Our paper reflects on learning in higher education during the Covid-19 pandemic, which has forced many institutions to adopt remote classes. The pandemic gave visibility to failures and successes in this area. Therefore, we show a brief overview of higher education to understand it in this moment of social isolation. The experiences reported here show different paths: that of the teacher, who becomes a student to learn new demands, that of the manager, who plans to support the teacher used to face-to-face classes and that of the mediating teacher, who observes the student as the protagonist of the learning process. In all the trajectories, we observed a trail with no return: the need for the (re) birth of teaching and the development of active methodologies to improve the quality of learning.

Keywords: pandemic; experiences; learning; coronavirus; remote teaching.
Recebido: 30/09/2020

Aprovado: 18/11/2020 


\section{NO MEIO DO CAMINHO, UMA PANDEMIA}

Em meados de março de 2020, as instituições de educação superior (IES) cancelaram suas aulas presenciais em razão da pandemia da Covid-19. Com a informação de que o isolamento social teria de ser prorrogado por mais tempo para evitar um número ainda maior de mortes por causa do coronavírus que provoca doenças respiratórias, as instituições de ensino e de pesquisa brasileiras passaram a colocar em prática algumas estratégias de ensino.

A maioria implantou o ensino remoto de forma quase instantânea, simplesmente transpondo a aula presencial para o ambiente digital, sem considerar as necessidades de mudanças. Como resultado, elas conseguiram estudantes entediados e professores estressados. Outras passaram a ofertar ações de qualificações a seus docentes. A falta de domínio técnico não foi o único problema encontrado pelos gestores institucionais, já que muitas falhas do ensino presencial são repetidas no on-line. No entanto, nem tudo tem sido tropeço no meio desse caminho. Professores, sobretudo os que pesquisam as transformações da educação há mais tempo, compartilharam de diferentes formas (oficinas, cursos, minicursos e lives) o seu conhecimento para contribuir com seus colegas de profissão na nova missão: colocar em prática o ensino remoto.

Para Selma Garrido Pimenta ${ }^{1}$, o ensino chamado de remoto, realizado à distância com a aplicação de tecnologias de forma temporal e com ferramentas síncronas, "segue as mesmas bases da educação presencial só que a distância [...] tende a ser transmissivo: praticamente, transpõe o presencial para o remoto".

Com a rapidez com que algumas IES transpuseram o ensino presencial para o remoto durante a pandemia, a ideia da incorporação de estratégias mais ativas se afastou do seu propósito, sem uma reflexão ou planejamento de atividades a serem desenvolvidas com o apoio de pessoal qualificado, com políticas de acesso, de acompanhamento e de avaliação compatíveis para estudantes e profissionais da educação que estão em lugares e tempos diversos².

Entre as dificuldades encontradas nesse caso estão a compreensão de como replanejar uma disciplina ou reconstruir as aulas numa perspectiva ativa, que combine atividades on-line, mediadas por tecnologias digitais, e off-line e que possam ser individuais e em equipe. Como preconiza o ensino híbrido, estimula-se a reconfiguração da sala de aula e do papel desempenhado por docentes e discentes, "por isso a educação formal é cada vez mais blended, misturada, híbrida, porque não acontece só no espaço físico da sala de aula, mas nos múltiplos espaços do cotidiano, que incluem os digitais"3.

Neste artigo, procuramos relatar um pouco sobre a nossa experiência em cursos que qualificam professores para os novos desafios do século XXI, sobre a preocupação dos gestores institucionais com a formação docente e sobre a importância das metodologias ativas no processo de aprendizagem. Não vamos falar apenas das pedras encontradas no caminho neste momento
1. Vivenciando $2020-$ Modelos de ensino: responsabilidades institucionais e individuais Mesa-redonda com Selma Garrido Pimenta, Soely Aparecida Jorge Polydoro, Shigeru Miyagawa, Dagma Venturini Abramides. Publicado pelo canal Pró-Reitoria de Pós-Graduação - USP. [S. I.: s. n.], 2020. Disponível em: https://www.youtube. $\mathrm{com} / \mathrm{watch}$ ?reload $=9 \& \mathrm{v}=-$ wpVuKMGor1c\&list=PLBtF8ROa1urEO-eb6Kzeuf6QvljJJ67N6\&index=3\&$\mathrm{t}=0$ s. Acesso em: 6 jul. 2020.

2. MORAN, José. Mudando a educação com metodologias ativas. In: SOUZA, Carlos Alberto de; MORALES, Ofelia Elisa Torres. Convergências Midiáticas, Educação e Cidadania: aproximações jovens. Ponta Grossa: UEPG, 2015. p. 15-33. Disponivel em: http://www2. eca.usp.br/moran/wp-content/uploads/2013/12/mudando_moran.pdf. Acesso em: 6 jul. 2020.

3. Ibidem, p. 16. 
4. CASTELLS, Manuel. A sociedade em rede: A era da informação: economia, sociedade e cultura. São Paulo: Paz e Terra, 1999. v. 1.

5. MASETTO, Marcos Tarciso. Metodologias ativas no ensino superior: para além da sua aplicação, quando fazem a diferença na formação de profissionais? Revista e-Curriculum, São Paulo, v. 16, n. 3, p. 650-667, 2018. DOI: 10.23925/1809-3876.2018v1 6i3p650-667.

6. MACHADO, Nílson José. Educação: autoridade, competência e qualidade. São Paulo: Escrituras, 2016.

7.ZABALZA, Miguel Ángel. $O$ ensino universitário: seu cenário e seus protagonistas. Porto Alegre: Artmed, 2007.

8. FREIRE, Paulo. Pedagogia da autonomia: saberes necessários à prática educativa. 2. ed. São Paulo: Paz e Terra, 1997.

9. GIL, Antonio Carlos. Didática do ensino superior. São Paulo: Atlas, 2013.

10. MASETTO, Marcos Tarciso ; ZUKOWSKY-TAVARES, Cristina. Formação de professores para currículos inovadores no ensino superior: um estudo num curso de Direito. Revista e-Curriculum, São Paulo, v. 13, n. 1, p. 5-27, 2015. Disponível em: http://revistas.pucsp. br/index.php/curriculum/ article/view/22460. Acesso em: 7 fev. 2020.

11. MASETTO, Op. cit. 12. MORAN, Op. cit. de isolamento social, mas sobretudo destacar experiências que colocam o processo de aprendizagem em discussão. Nesta trilha, é importante fazer um panorama da educação superior para poder compreendê-la em contexto de convergência tecnológica.

\section{DAS TRILHAS PERCORRIDAS: PANORAMA DA EDUCAÇÃO SUPERIOR}

A formação de nível superior tem sido influenciada pelas mudanças ocorridas na sociedade a partir dos anos 1950, que compreenderam questões culturais, econômicas e políticas, como destaca Castells ${ }^{4}$. Essas transformações colocaram a educação frente ao dilema da tradição, por um lado, e da inovação, por outro. Nesse cenário dicotômico, espera-se um equilíbrio entre as novidades que chegaram com as tecnologias digitais e as bases que estabeleceram o conhecimento científico. Esse diálogo é necessário para evitar extremos entre um viés instrumental ou um muito teórico.

Acredita-se que o momento atual ainda é um período de transição da concepção tradicional para a contemporânea em educação, então, muitas vezes, a proximidade temporal impede de se analisar melhor o que se vivencia. Contudo, quem está nas salas de aulas vê um perfil de estudante diferente, por isso uma adaptação a novos contextos é premente ${ }^{5}$. Um dos desafios da docência hoje é despertar no discente uma motivação para o aprender.

No ambiente contemporâneo, o estudante conta com dispositivos tecnológicos que facilitam o acesso à informação; no entanto, isso não quer dizer conhecimento, como afirma Machado ${ }^{6}$. De qualquer forma, esse aspecto muda o modelo de um ensino transmissor de conteúdo, pois este deve se voltar à aprendizagem do discente ${ }^{7}$; o estudante precisa ser mais ativo no processo, ser despertado para o conhecimento.

A ideia atual da educação é de uma formação contrária ao acúmulo de conhecimentos, na concepção bancária de Freire ${ }^{8}$, porque agora ela é voltada à práxis, à mobilização de saberes para construção de conhecimentos e não baseada apenas na transmissão deles.

No entanto, a prática docente tradicional ainda está presente nos cursos superiores, como coloca $\mathrm{Gil}^{9}$, derivada de um processo histórico de fragmentação dos saberes, proposta pela ciência moderna, que criou estruturas arraigadas e que não se alteraram rapidamente. Aos poucos, foi se incorporando a flexibilidade aos currículos, dos quais também se espera interdisciplinaridade e integração da teoria e da prática, para superar tal fragmentação em prol da articulação de conhecimentos de várias áreas ${ }^{10}$.

Políticas públicas educacionais têm definido suas diretrizes pela adaptação a esse cenário, com o efeito perverso de precarização na educação. Nessa realidade, pede-se a adoção de práticas diferenciadas de ensino-aprendizagem ${ }^{11,12}$, como trabalho por projetos, ensino com pesquisa, resolução de problemas, aula 
invertida, gamificação, aprendizagem maker, simulação, aprendizagem entre pares, entre outros métodos considerados como estratégias ativas, mais compatíveis com a atualidade. Todavia, nem sempre se contou com os investimentos ou formação decente necessários para sua aplicação.

Essas práticas estão sendo bastante incentivadas no contexto de uma educação mediada por tecnologias digitais, como já acontece na educação a distância ou com o ensino híbrido. Nesses casos, valoriza-se a aprendizagem em tempos e espaços diversos ou se combinam atividades presenciais e não presenciais $^{13,14}$, sejam síncronas ou assíncronas, com ferramentas ou plataformas digitais (como Google, Skype, Zoom, Microsoft Teams), aplicativos (WhatsApp), mídias convencionais e digitais (rádio, televisão, Facebook, YouTube) ou ambientes virtuais exclusivamente de aprendizagem (Moodle).

Alguns desafios enfrentados pela educação a distância também podem equivaler aos que foram sentidos na urgência de adaptar o ensino presencial para o remoto, como se depreende a partir de Moran: "Muitos docentes e tutores não se sentem confortáveis nos ambientes virtuais, não têm a disciplina necessária para gerenciar fóruns, prazos, atividades. A falta de contato físico os perturba. O mesmo acontece com parte dos alunos, pouco autônomos, com deficiências na formação básica"15. Os estudantes também, como pontua o autor, não se adaptam aos ambientes virtuais e sentem falta da presença física da turma.

Fora essas questões levantadas, há outras que ressoam nesse momento de pandemia. Muitas vezes, por exemplo, o quesito infraestrutura passou a ser responsabilidade de docentes e discentes, como a aquisição pessoal de equipamentos, softwares e maior banda de internet em casa. De acordo com Zabalza ${ }^{16}$, isso nem sempre é possível devido às desigualdades existentes num país como o Brasil. Outro aspecto a ser abordado é a saúde física e mental de professores e estudantes num contexto de incertezas socioeconômicas, mutação na situação familiar e riscos à qualidade de vida de todos.

Com esse cenário, é possível que existam docentes que agora tiveram mais facilidade em relação a outros colegas em se adaptar a mudanças, seja em função de afinidade com as tecnologias digitais seja por terem se qualificado ao longo do tempo para incluir modalidades emergentes em suas aulas. No entanto, de algum modo, como destaca Zabalza ${ }^{17}$, cada vez mais as ferramentas virtuais vão estar presentes nas aulas, inclusive como herança deste período pandêmico.

\section{EXPERIÊNCIAS DE ENSINO DESTE PERÍODO PANDÊMICO}

Neste artigo, destacaremos algumas experiências de quem está envolvido com cursos, oficinas e lives enquanto docente e gestor. Na internet, sobretudo no final do primeiro semestre de 2020, foram ofertadas as mais diferentes modalidades de capacitação para professores universitários de todo país.
13. Ibidem

14. Vivenciando $2020 \ldots$, Op. cit.

15. MORAN, Op. cit., p. 28.

16. FERRARI, Maria Aparecida; MARTINS, Juliane. Anobre missão dos professores universitários no séculoXXI: uma visão contemporânea vinda da Espanha. Entrevistado: Miguel Ángel Zabalza. Organicom, São Paulo v. 17, n. 32, p. 20-28, 2020 DOI: 10.11606/issn.22382593.organicom.17.170918. 17. Ibidem. 


\subsection{O treinamento docente: a corrida.}

As lives - transmissões ao vivo em redes sociais - sobre todos os temas invadiram a internet, com o apoio de instituições de ensino e de pesquisa. No entanto, no início da pandemia, a maior parte delas foi organizada de forma independente por professores preocupados com diferentes temas, como interação com estudantes nas plataformas digitais e avaliações on-line. Aqui o nosso foco está na preocupação deste docente, que parece ficar ainda mais ansioso nesta corrida para encontrar uma solução para a prática da docência no ensino remoto. Por isso, abordamos algumas das preocupações que apareceram nas mensagens dessas transmissões ao vivo com especialistas em educação. Por questões éticas de pesquisa, não vamos identificar esses professores e nem as lives das quais participaram.

Por meio das mensagens do público, é possível observar a reclamação sobre a falta de tempo para planejamento de aulas e de um espaço apropriado para a transmissão do ensino remoto, uma vez que a maioria foi obrigada a fazer da sua casa uma sala de aula improvisada e sem nenhum apoio. Muitos docentes também contam que estão exaustos com a mudança brusca na rotina e o aumento da carga horário de trabalho. Ainda assim, não deixam de buscar aperfeiçoamento e de explorar ferramentas que possam melhorar a qualidade do ensino-aprendizagem. "Tivemos que nos adaptar de forma emergencial", destaca uma das professoras, que não conhecia e nem tinha recebido treinamento para utilizar a plataforma de ensino virtual adotado por sua instituição. Outro docente diz que aproveita para se atualizar com as ofertas de eventos sobre educação disponíveis na internet.

Instituições de todo o mundo têm oferecido oficinas e cursos gratuitos para professores de todos os níveis de ensino. A preocupação com o discente tem sido tema frequente nestes cursos. Em um deles, sobre o uso de recursos tecnológicos no ensino remoto, o docente é preparado a responder o estudante que reclama do excesso de conteúdo disponibilizado na plataforma de ensino.

18. D'ANDREA, Carlos. Pesquisando plataformas online: conceitos e métodos. Salvador: EdUFBA, 2020.

19. CASTELLS, op. cit.

20. Os Estudos da Plataforma têm uma visão mais crítica, procurando observar de forma mais refinada a articulação entre as dimensões tecnológicas, políticas e econômicas das redes sociais (D'ANDREA, 2020), evidentemente sem esquecer de analisar as apropriações culturais de seus usuários.

21. CABRAL, Ana Lucia Tinoco; SEARA, Isabel Roberedo; GUARANHA, Manoel Francisco (Orgs.). Descortesia e cortesia: expressão de culturas. São Paulo: Cortez, 2017.
Neste momento, o professor ainda é levado a refletir sobre o novo cenário da comunicação, destacando o crescimento das redes sociais digitais que propagam os mais diversos conteúdos numa velocidade nunca imaginada. Carlos d'Andrea ${ }^{18}$ aponta que, no caminho da sociedade em rede destacada por Castells ${ }^{19}$ para a sociedade da plataforma ${ }^{20}$, houve um rompimento da tecnoutopia. Os limites entre o público e o privado são borrados e, como também destaca d'Andrea, aumentaram as práticas tóxicas e de intolerância.

Nas redes sociais digitais, surge a cultura do cancelamento que, de modo simplificado, significa que as pessoas reagem mal a um comentário contrário ao que pensam a ponto de deixarem de seguir alguém e/ou incentivarem a crítica coletiva. Diante dessa rede de ódio, como o professor deve agir? Com base em Cabral, Seara e Guaranha ${ }^{21}$, os docentes em curso foram convidados a criar uma resposta para uma mensagem bastante inapropriada de um estudante. A mensagem, recortada do referido livro, mostrava a quebra de polidez 
na interação, tal como ocorre nas redes sociais digitais. A grande maioria dos professores não ignorou a forma descortês do discente e respondeu de modo polido, chamando a atenção que nas atividades acadêmicas é necessário utilizar a língua culta e, de forma enfática, exigia educação e respeito. Neste exercício, o momento estressante da pandemia também foi considerado. Os docentes acreditam que é preciso flexibilizar a exigência e se envolver com o problema do outro. Sem focar na agressividade, os professores detalharam o funcionamento de sua disciplina ao suposto estudante, oferecendo apoio caso ele tivesse qualquer dificuldade.

Após o exercício, os docentes iniciaram um debate sobre a situação que enfrentam agora nas aulas remotas. As mensagens ofensivas, como a do referido exercício proposto, são mais comuns do que se possa imaginar. Durante a pandemia, opina uma das professoras em curso, parece que os estudantes estão mais estressados. Esse fenômeno nas redes sociais, no entanto, vem sendo combatido há bastante tempo por várias organizações, como o Conselho da Europa que editou, em 2016, um manual para combater o ódio nas redes sociais por meio da educação para os direitos humanos. Esse manual traz vários temas que podem ser discutidos com discentes. Entre eles, o da liberdade de expressão, um direito humano fundamental, como evidencia o manual que observa: "[...] a liberdade de expressão não é um direito 'absoluto' que se aplique em todos os casos, sem limites é um direito que tem de se equilibrar com os direitos das outras pessoas, ou com o bem da sociedade como um todo" ${ }^{22}$.

Nas aulas remotas, as mensagens agressivas parecem ter se intensificado durante a pandemia. A experiência dos professores tem contornado essa descortesia com paciência e educação, conforme os exercícios dos docentes. A maioria deles compreende que as pessoas estão abaladas emocionalmente e, portanto, podem ficar mais agressivas na pandemia.

Outro problema que alguns professores enfrentam no período de isolamento social é a invasão de hackers nas salas virtuais ${ }^{23}$ para tumultuar o ambiente e, sobretudo, ofender as pessoas. Com isso, iniciativas para cuidar da saúde mental dos docentes têm surgido no país. No Distrito Federal, por exemplo, os professores da rede pública de ensino estão recebendo apoio psicológico e eles são orientados a cuidar da saúde emocional para evitar o impacto provocado pela mudança de rotina ${ }^{24}$.

Na Universidade Federal do Paraná (UFPR), o projeto ConVida, criado em junho de 2019, também tem realizado várias atividades para tornar os espaços da instituição mais acolhedores para o bem-estar e a saúde de docentes, técnicos, estudantes e comunidade externa. Desde a suspensão das aulas presenciais, o ConVida passou a desenvolver várias ações para os públicos citados não se sentirem sozinhos. Os encontros virtuais convidam especialistas para debater vários temas que afetam o dia a dia das pessoas, procurando apresentar algumas soluções. Neste artigo, destacamos o cuidado com os professores, que vão desde bate-papos sobre emoções e alimentação até a trocas de soluções tecnológicas criativas para usar nas plataformas digitais.
22. ódio Não! - Movimento Contra o Discurso de ódio. Referências: manual para o combate do discurso de ódio online através da educação para os direitos humanos. Lisboa: Fundação Calouste Gulbenkian; Estrasburgo: Conselho da Europa, 2016, p. 70.

23. Hackers invadem sites e aplicativos para tumultuar palestras e reuniões. Reportagem de Elaine Bast para o telejornal Bom Dia Brasil. Rio de Janeiro: Rede Globo de Televisão, 2020. 1 vídeo (4 min). Disponível em: https://globoplay.globo.com/v/8799319/?s=0s. Acesso em: 14 jan. 2021.

24. RIOS, Alan. Professores têm atendimento virtual com psicólogos durante a pandemia. Correio Braziliense, Brasília, DF, 22 jul. 2020. 
Períodos especiais são ofertados aos discentes com disciplinas obrigatórias e/ ou optativas na educação superior pública e privada. Neste período, o importante é manter o vínculo com os estudantes. "Ainda prefiro mil vezes a educação presencial. No entanto, as aulas remotas estão funcionando para mim. Nas aulas remotas que eu participo, os meus colegas comentam que perdem o foco", conta a estudante 1 de um curso superior de uma instituição pública em depoimento durante o mês de agosto para esta pesquisa. Ela sente que quando todos estão com suas câmeras ligadas a interação parece fluir melhor. "A sala parecer ficar mais 'real", observa. As atividades assíncronas são bem recebidas pela discente. "Fazer atividades semanais para os temas apresentados também vejo como um ponto muito positivo, pois desse modo o conteúdo não fica perdido em meio de tanta coisa”.

A estudante 2 também declara que a concentração tem sido um problema para a maioria de seus colegas de turma. As distrações são as mais diversas, como os ruídos em casa e/ou as mensagens que chegam no celular dos próprios colegas. Nas aulas presenciais, o professor tenta controlar o uso do celular em sala de aula. Longe dos olhos do docente, o controle passa a ser exclusivamente do discente. "Estou aproveitando, mas é difícil ficar $100 \%$ na aula. Se alguém comenta algo no grupo de WhatsApp da turma, sempre rola uma conversa”. Por isso, alguns estudantes têm preferido as aulas assíncronas, pois na plataforma virtual é possível se programar e ter um ambiente mais tranquilo.

No segundo semestre de 2020, no final de setembro, percebemos que os docentes ganharam mais desenvoltura nas lives e nas aulas on-line. E os estudantes do nível superior, sobretudo aqueles que precisam conciliar o trabalho remoto e a educação a distância, já começam a reclamar das atividades que precisam realizar para cada disciplina e da falta de convívio diário e presencial com colegas e professores.

\subsection{Planejamento para ensino remoto: a experiência institucional na UFPR.}

As instituições têm colaborado com a formação continuada, ampliando o número de cursos e oficinas para colocar o Ensino Remoto Emergencial (ERE) em prática e, assim, sugerir atividades pedagógicas que estimulem a aprendizagem nesta modalidade e procure suprir a falta de contato com a turma e professores. Aqui apresentamos um relato de como algumas dessas ações foram efetivadas na UFPR.

Frente aos desafios de retomada do calendário acadêmico de forma regular, às questões de acessibilidade digital e à impossibilidade de práticas laboratoriais presenciais, a UFPR adotou a estratégia de oferta de disciplinas em períodos especiais. Assim, disciplinas dos currículos de todos os cursos puderam ser ministradas no ensino remoto de forma voluntária pelos professores após a aprovação de cada colegiado. Os estudantes, que poderiam cancelar a matrícula a qualquer momento, também conseguiram escolher se fariam ou não a matrícula. 
$\mathrm{Na}$ universidade em questão, foram adotadas diversas ações. Aqui elencamos algumas para exemplificar como a UFPR atuou na condução do ensino remoto. Esse processo foi conduzido pela Prograd (Pró-Reitoria de Graduação e Ensino Profissional), com ações conjuntas com a Prae (Pró-Reitoria de Assuntos Estudantis) para a viabilidade de acesso digital aos discentes. Dentro da Prograd, a Cipead (Coordenadoria de Integração de Políticas de Educação a Distância) foi responsável pelas ações de qualificação docente, embora inúmeras oficinas e cursos continuassem a ser organizadas por iniciativa própria de professores. A coordenadoria criou o "Projeto Saberes Online na Pandemia", que incluiu desde conteúdo nas redes sociais on-line compartilhado de outras instituições, até cursos e web oficinas ministradas em iniciativa própria e em parceria com os NTEs (Núcleos de Tecnologias Educacionais) dos setores e com a Progepe (Pró-Reitoria de Gestão de Pessoas).

O trabalho começou com a discussão de uma minuta de resolução que regulamentaria o período especial. Ao mesmo tempo, coordenações de curso realizaram levantamentos junto a professores e estudantes sobre a acessibilidade digital e a viabilidade do ensino remoto. Como a adesão ao período especial foi voluntária, os cursos conduziram essa pesquisa de forma independente em um primeiro momento. Depois, a Prae realizou outra pesquisa com os discentes para planejar a disponibilização de computadores e internet àqueles que precisassem. Para exemplificar o trabalho das coordenações, relatamos aqui os procedimentos realizados no curso de Comunicação Institucional (CI).

A coordenação aplicou duas pesquisas sobre a acessibilidade digital em caso da implantação do ensino remoto, uma com professores e outra com discentes. Em meados de março, fez ainda uma webconferência com o corpo docente para discutir o assunto. A pesquisa com os estudantes foi disparada pelos grupos de Facebook e, posteriormente, por e-mail, obtendo o resultado disponível na Tabela 1. Os discentes com acesso limitado ou sem acesso à internet puderam participar do edital aberto pela Prae para adquirir equipamento e pacote de dados.

\section{Tabela 1: Acessibilidade digital}

\begin{tabular}{c|c|c|c} 
Matriculados & Respondentes & Acesso limitado & Sem acesso \\
\hline 140 & 137 & 4 & 2 \\
\hline \multicolumn{2}{|c}{ Fonte: Coordenação $\mathrm{Cl}(2020)}$.
\end{tabular}

Os 12 docentes do curso de Comunicação Institucional com disciplinas no primeiro semestre de 2020 responderam à pesquisa elaborada pela coordenação. Seis deles não tinham usado ainda a plataforma Moodle, mas estavam dispostos a usar o ambiente virtual de aprendizagem da instituição (AVA UFPR Virtual) depois de treinamento adequado. Todos os professores pesquisados já utilizavam outros dispositivos de comunicação com os estudantes, como e-mail, WhatsApp, Facebook, Microsoft Teams e sites. A Tabela 2 mostra o número de disciplinas ministradas no primeiro semestre de 2020 antes do isolamento social, depois as 
25. UNIVERSIDADE FEDERAL DO PARANÁ - UFPR. Pró-reitoria de Graduação e Educação Profissional. Balanço período especial. Curitiba: UFPR, 2020a. 6 slides, color. Disponível em: http://www.prograd. ufpr.br/portal/wp-content/ uploads/2020/09/UFPR PE_Audiencia_20200922_ BalancoPE-2.pdf. Acesso em: 22 set. 2020.

26. UNIVERSIDADE FEDERAL DO PARANÁ - UFPR.

Pró-reitoria de Graduação e Educação Profissional.

Saberes Online na Pandemia: relatório CIPEAD/ PROGRAD. Curitiba: UFPR 2020c. 9 slides, color. Disponível em: http://www. prograd.ufpr.br/portal/wp-content/uploads/2020/09/ Relatorio-CIPEAD-PROGRAD-1.pdf. Acesso em: 22 set. 2020. que poderiam ser oferecidas no ERE de acordo com os docentes e, finalmente, as ofertadas em período especial. Das 305 vagas abertas nas disciplinas, 244 foram preenchidas.

\section{Tabela 2: curso de Comunicação Institucional da UFPR no Ensino Remoto Emergencial}

\begin{tabular}{c|c|c} 
Número de disciplinas & Disciplinas para o ERE & Ofertadas \\
\hline 21 & 14 & 8 obrigatórias \\
& & 2 optativas \\
& & Total: 10 \\
\hline
\end{tabular}

Num balanço do primeiro período especial na UFPR, ocorrido de 26 de junho a 29 de junho de 2020, a Prograd ${ }^{25}$ destacou que as vagas ocupadas em todos os cursos da instituição representaram 35\% das ocupadas no primeiro semestre regular de 2020 e os estudantes com matrículas no mesmo período representaram $71 \%$ dos discentes com matrícula no primeiro semestre de 2020. A principal dificuldade, ainda em discussão na universidade, é com relação às disciplinas práticas e laboratoriais que não têm a possibilidade de oferta de forma remota.

Outro relatório apresentado pela UFPR mostra que a procura voluntária dos docentes por ações de qualificações desde o início da pandemia foi grande, conforme a Tabela 3. Segundo o relatório da Cipead, vinculada à Prograd, os cursos mais procurados pelos professores foram recursos tecnológicos, educação híbrida, jogos digitais, acessibilidade e cursos específicos sobre o AVA UFPR Virtual.

\section{Tabela 3: Ações de qualificação}

\begin{tabular}{c|c|c|c} 
Cursos & Oficinas & Atividades dos NTEs & Total de participantes \\
\hline 1.128 & 1.633 & 312 & 3.073 \\
\hline
\end{tabular}

Algumas ações de gestão realizadas antes do isolamento social foram importantes para a implantação do ensino remoto. O relatório da Cipead destaca várias delas, mas aqui apresentamos as seguintes: a adoção, pela UFPR, do Office 365 e do uso do Microsoft Teams para atividades acadêmico/administrativas; lançamento dos ambientes virtuais de aprendizagem UFPR Virtual (para cursos internos) e UFPR Aberta (Moocs abertos às comunidades interna e externa); Projeto CLibras (plataforma para intérpretes e inclusão de pessoas com deficiência); e assessoria docente por meio da sala de assessoria pedagógica da Cipead online e Projeto NTEs em Rede. Como em todas as ações de uma instituição de ensino, houve muitos questionamentos por parte de professores e de estudantes. As perguntas mais frequentes estavam relacionadas às possíveis consequências das tomadas de decisão da gestão, como: será que é o momento certo para mudar interfaces gráficas? Como os dados gerados em uma plataforma digital privada serão utilizados? Neste artigo não vamos apresentar uma 
análise dessas ações, mas é importante mostrar que também houve conflito nestas interações.

Uma comissão de coordenadores, professores e estudantes, organizada pela Prograd, também realizou pesquisa de avaliação sobre o ensino emergencial na instituição ${ }^{27}$. Dos 1.219 (48,07\%) docentes respondentes, $75 \%$ ministraram aula na graduação no período especial e $42 \%$ destes também assumiram aulas na pós-graduação. Logo, as atividades (acadêmicas e administrativas) se acumularam de forma exponencial.

Nesta mesma pesquisa, discentes e docentes responderam a seguinte questão: Como você avalia sua experiência com o ensino remoto emergencial? As respostas geraram uma imagem que destacou as palavras mais citadas, demonstrando pontos considerados positivos (em azul) e negativos (em cinza).

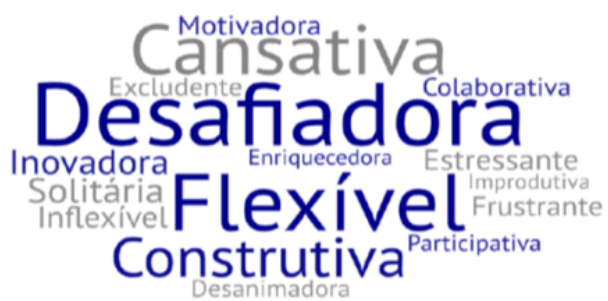

Docentes

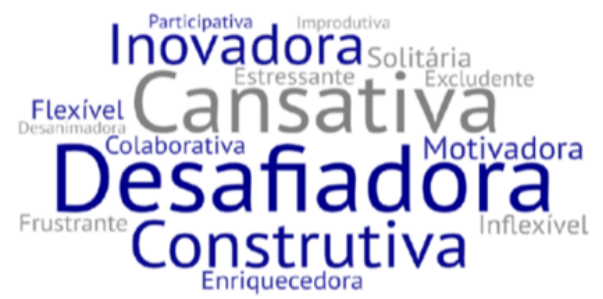

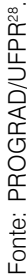

Figura 1: Pesquisa Ensino Remoto Emergencial UFPR

Tanto para os docentes como para os discentes, a experiência foi desafiadora e cansativa como mostra a Figura 1. Essa modalidade de ensino tornou pesado o cotidiano de professores e estudantes. As atividades de ensino remoto, a maioria ministrada de forma condensada, exigiu dos discentes uma rotina de estudos que antes era diluída no ensino presencial. $\mathrm{E}$ a adaptação das aulas remotas exigiu produção de material didático apropriado, ampliando as horas do docente na frente do computador.

Durante o ensino remoto também foi lançado o Programa de Monitoria Digital, que possibilitou, por meio de edital, selecionar um monitor bolsista que já tivesse cursado a disciplina a ser ministrada. Muitos desses monitores, com fluência no uso das tecnologias adotadas no ensino remoto, auxiliariam tanto professores quanto estudantes, evidenciando um ambiente on-line colaborativo e de aprendizado mútuo.

\section{CONSIDERAÇÕES FINAIS}

A pandemia tem afetado o cotidiano das pessoas e, consequentemente, da educação superior. Neste artigo, procuramos refletir um pouco sobre as

27. UNIVERSIDADE FEDERAL DO PARANÁ - UFPR. Pró-reitoria de Graduação e Educação Profissional. Resultados da pesquisa de avaliação: ensino remoto emergencial. Curitiba: UFPR, 2020b. 13 slides, color. Disponível em: http://www.prograd.ufpr. br/portal/wp-content/ uploads/2020/09/Resultados-Pesquisa-de-Avaliacao-do-ERE.pdf. Acesso em: 22 set. 2020.

28. Ibidem. 
discussões acerca dos papéis assumidos por professores e estudantes na educação superior. Também apresentamos algumas experiências do ERE, apontando soluções e experiências encontradas por docentes, discentes e instituições.

O fato é que tanto estudantes quanto professores estão cansados com a rotina imposta por esta pandemia, mas não desistiram de encontrar uma solução para aprender. Percebemos que muitos docentes abrem mais possibilidades de diálogo com os estudantes, que, por sua vez, se esforçam para propor soluções. Juntos, eles se reconfiguram e transformam a prática de ensino. A nossa intenção, neste artigo, foi evidenciar essas mudanças e refletir um pouco sobre os bastidores da educação superior em tempo de pandemia. Ainda é cedo para estudar os efeitos dessas ações emergenciais.

Práticas pedagógicas que estimulam o envolvimento do discente no processo ensino-aprendizagem e permitem que ele seja responsável pela própria aprendizagem são consideradas métodos ativos. A utilização deles depende da ação docente em ultrapassar a ideia do repasse de conteúdos. Nesse âmbito, as tecnologias digitais podem ser aliadas, tendo como potencialidade modificar o papel do professor, daquele que passa informação para o de orientador. Além disso, colabora para que os estudantes ultrapassem o papel de receptores passivos.

Compreendemos que o isolamento na pandemia intensificou a busca por soluções tecnológicas. Independente das pedras encontradas no caminho, acreditamos que essa busca acelerou o processo de aprendizagem do professor e do estudante.

\section{REFERÊNCIAS BIBLIOGRÁFICAS}

CABRAL, Ana Lucia Tinoco; SEARA, Isabel Roberedo; GUARANHA, Manoel Francisco (Orgs.). Descortesia e cortesia: expressão de culturas. São Paulo: Cortez, 2017.

CASTELLS, Manuel. A sociedade em rede: A era da informação: economia, sociedade e cultura. São Paulo: Paz e Terra, 1999. v. 1.

D'ANDREA, Carlos. Pesquisando plataformas online: conceitos e métodos. Salvador: EdUFBA, 2020.

FERRARI, Maria Aparecida; MARTINS, Juliane. A nobre missão dos professores universitários no século XXI: uma visão contemporânea vinda da Espanha. Entrevistado: Miguel Ángel Zabalza. Organicom, São Paulo, v. 17, n. 32, p. 20-28, 2020. Disponível em: https://doi.org/10.11606/issn.22382593.organicom.17.170918. Acesso em: 6 jul. 2020.

FREIRE, Paulo. Pedagogia da autonomia: saberes necessários à prática educativa. 2. ed. São Paulo: Paz e Terra, 1997.

GIL, Antonio Carlos. Didática do ensino superior. São Paulo: Atlas, 2013. 
Hackers invadem sites e aplicativos para tumultuar palestras e reuniões. Reportagem de Elaine Bast para o telejornal Bom Dia Brasil. Rio de Janeiro: Rede Globo de Televisão, 2020. 1 vídeo (4 min). Disponível em: https://globoplay.globo.com/v/8799319/?s=0s. Acesso em: 14 jan. 2021.

MACHADO, Nílson José. Educação: autoridade, competência e qualidade. São Paulo: Escrituras, 2016.

MASETTO, Marcos Tarciso. Metodologias ativas no ensino superior: para além da sua aplicação, quando fazem a diferença na formação de profissionais? Revista e-Curriculum, São Paulo, v. 16, n. 3, p. 650-667, 2018. DOI: 10.23925/1809-3876.2018v16i3p650-667.

MASETTO, Marcos Tarciso; ZUKOWSKY-TAVARES, Cristina. Formação de professores para currículos inovadores no ensino superior: um estudo num curso de Direito. Revista e-Curriculum, São Paulo, v. 13, n. 1, p. 5-27, 2015. Disponível em: http://revistas.pucsp.br/index.php/curriculum/article/ view/22460. Acesso em: 7 fev. 2020.

MORAN, José. Mudando a educação com metodologias ativas. In: SOUZA, Carlos Alberto de; MORALES, Ofelia Elisa Torres. Convergências Midiáticas, Educação e Cidadania: aproximações jovens. Ponta Grossa: UEPG, 2015. p. 15-33. Disponível em: http:/ /www2.eca.usp.br/moran/wp-content/ uploads/2013/12/mudando_moran.pdf. Acesso em: 6 jul. 2020.

ódio Não! - Movimento Contra o Discurso de ódio. Referências: manual para o combate do discurso de ódio online através da educação para os direitos humanos. Lisboa: Fundação Calouste Gulbenkian; Estrasburgo: Conselho da Europa, 2016.

RIOS, Alan. Professores têm atendimento virtual com psicólogos durante a pandemia. Correio Braziliense, Brasília, DF, 22 jul. 2020.

UNIVERSIDADE FEDERAL DO PARANÁ - UFPR. Pró-reitoria de Graduação e Educação Profissional. Balanço período especial. Curitiba: UFPR, 2020a. 6 slides, color. Disponível em: http:/ / www.prograd.ufpr.br/portal/wp-content/ uploads/2020/09/UFPR_PE_Audiencia_20200922_BalancoPE-2.pdf. Acesso em: 22 set. 2020.

UNIVERSIDADE FEDERAL DO PARANÁ - UFPR. Pró-reitoria de Graduação e Educação Profissional. Resultados da pesquisa de avaliação: ensino remoto emergencial. Curitiba: UFPR, 2020b. 13 slides, color. Disponível em: http://www.prograd.ufpr.br/portal/wp-content/uploads/2020/09/ Resultados-Pesquisa-de-Avaliacao-do-ERE.pdf. Acesso em: 22 set. 2020.

UNIVERSIDADE FEDERAL DO PARANÁ - UFPR. Pró-reitoria de Graduação e Educação Profissional. Saberes Online na Pandemia: relatório CIPEAD/PROGRAD. Curitiba: UFPR, 2020c. 9 slides, color. Disponível em: 
http:/ / www.prograd.ufpr.br/portal/wp-content/uploads / 2020/09/ Relatorio-CIPEAD-PROGRAD-1.pdf. Acesso em: 22 set. 2020.

Vivenciando 2020 - Modelos de ensino: responsabilidades institucionais e individuais Mesa-redonda com Selma Garrido Pimenta, Soely Aparecida Jorge Polydoro, Shigeru Miyagawa, Dagma Venturini Abramides. Publicado pelo canal Pró-Reitoria de Pós-Graduação - USP. [S. l.: s. n.], 2020. Disponível em: https:/ / www.youtube.com/watch?reload=9\&v=wpVuKMGor1c\&list=PLB tF8ROa1urEO-eb6Kzeuf6QvIjJJ67N6\&index=3\&t=0s. Acesso em: 6 jul. 2020.

ZABALZA, Miguel Ángel. O ensino universitário: seu cenário e seus protagonistas. Porto Alegre: Artmed, 2007. 